\title{
Analysis of Consumers' Intention Values in the Choice of a Mobile Service Provider
}

\author{
Park Thaichon \\ S P Jain School of Global Management, Sydney, Australia \\ Kartikay Sharma \\ S P Jain School of Global Management,Sydney, Australia \\ Komal Raina \\ S P Jain School of Global Management, Sydney, Australia \\ Satyam Kapoor \\ S P Jain School of Global Management, Sydney, Australia
}

\begin{abstract}
This research aimed to explore the determinants of consumer intentions to purchase and switch in the mobile telecommunication industry in Australia. It adopted a qualitative, inductive approach to data collection using a sample of 21 Australian mobile service customers, identifying various determinants of overall service quality and values that play an important role in choosing a service provider. Based on the interview results, it was inferred that certain factors, including network coverage, price value, and voice and non-voice services, affect consumers' motivations to buy from or switch mobile service providers. Conversely, in-store service, information quality and website information support, and corporate social responsibility do not play a major role in consumers' decision. The findings enable the providers to make strategic decisions on service investment.
\end{abstract}

Keywords: Intention to switch, Intention to purchase, Voiceservice, Non-voice service, Mobile service provider, Australia

\section{Background of the Study}

Building a strong brand is of prime importance for any business. It is becoming more difficult to build value in the hi-tech service industry. This research aims to explore different aspects of technical capability and service quality and their impact on the overall perception of service quality, the perceived value, and the dimensions of consumer behavior,especially the intention to purchase and the intention to switch,inthe mobile services industry in Australia. The study of various determinants of overall service quality and consumers' intention values that come into play while 
choosing a service provider can enable providers to make strategic decisions on service investments.

Recruiting new customers cannot guarantee long-term success for a company, especially when that company cannot retain its customers (Wang \& Wu, 2012). Wang and $\mathrm{Wu}$ (2012) suggested that it is necessary to focus equally on customer acquisition and customer retention in order to boost company performance. Moreover, a 2\% increase in the customer retention rate is equal to a $10 \%$ decrease in the cost of customer acquisition in the mobile phone service industry in China (Han, Lu, \& Leung, 2012). This means that mobile service providers that can retain their customers do not have the pressure of acquiring new customers; thus, they can save resources that would otherwise go to expensive customer acquisition and increase profitability. In addition, service quality raises consumers' commitment to the brand (Thaichon, Lobo, Prentice \& Quach, 2014), and, as a result, they are more resistant to inducements to move to other brands (Thaichon \& Quach, 2015). Hence, service quality and customer satisfaction can help service providers to increase customer retention by decreasing the brand switching rate and maintaining the current customer base.

A mobile service provider is a company that provides mobile communication services to users of mobile devices like smart phones. Initiallyoffering voice services for communication between point $\mathrm{A}$ and point $\mathrm{B}$, companies gradually started offering other, non-voice services, like SMS, MMS, and the Internet. With the advent of new technology in the mobile services domain and the entry of new service providers, competition evolved as the main driver of the industry, with technology being taken for granted. With such a scenario in mind, various studies by different market researchers have pointed out and acknowledged the use of overall service quality as a tool to gain a competitive edge (Rust \&Chung, 2006). The network quality is one of the key parameters to judge the overall service quality in the mobile service industry (Thaichon, Lobo, \&Mitsis, 2014). However, with non-voice services contributing substantially to companies' revenues (Adegoke, 2002), they have become equally important as the traditional voice services offered by the telecommunication industry. Keeping in mind the above review of the different elements and taking into consideration a few of the elements from the "SERVQUAL" model (Parasuraman, Zeithmal, \& Berry, 1985), this study came up with the following technical and functional elements that will have a direct impact on the overall service quality:

- Network Quality

- Non-Voice Services

- Responsiveness

- Reliability

- Empathy

The above-mentioned key elements directly influence the overall service quality of a mobile service provider, which, in turn, has a direct impact on the perceived value or the customers' readiness to compromise in terms of costs (Parasuraman, Zeithmal, \& Berry, 1988). For stance, previous research evidences that network quality is an important driver of overall service quality in the Chinese telecommunications market (Lai et al., 2009). However, businesses should not only focus on network quality, but they should also pay attention to other aspect in order to enhance overall service 
quality perception. This study will look into this matter. Moreover, a study in China also proposed that responsiveness is an antecedent to the overall service quality in the mobile services sector (Wang et al., 2004). In addition, He and Li (2010) proposed that reliability andempathy are antecedents to the overall service quality in the mobile services sector.

\section{Literature Review}

\section{Network Quality}

Network quality includes the number of errors, downloading and uploading speed and system response time (Vlachos \&Vrechopoulos, 2008). In mobile phone networking service, the network quality can be discussed on call quality, coverage, and network, such as dropped calls, static and broken conversation during cellular phone calls (Asaari\&Karia, 2003). According to a study conducted by Shawn Steward, call breakage and static lead to frustrated and angry customers (Steward, 1993). Previous research confirms that network quality is one of the most important drivers of overall service quality in Chinese (Lai et al., 2009), and Korean mobile service provider markets (Kim \& Yoon, 2004). Taking all these factors into consideration, it can be said without a measure of doubt that the network quality has a major impact on the overall service quality.

\section{Non-Voice Services}

The prime benefit of non-voice services is that they allow a consumer to contact a fairly large number of people with very few transaction costs involved (Wishart, 2006). Infact, in a report byAdegoke(2002), the average revenue per user for companies such as $\mathrm{O} 2$, Orange, and T-mobile has been boosted by the rapid adoption of non-voice services. Oh et al. (2008) also mentioned that in the Australian mobile service provider market, the revenue from voice calling is decreasing and that from data services is rising rapidly. Non-voice services are one of the major factors that influence the selection of a mobile service provider and the brand loyalty associated with it (Paulrajan\&Rajkumar, 2011).

\section{Responsiveness}

Responsiveness refers to a service firm's willingness to help customers and provide a prompt service. It involves timeliness of service (He \& Li, 2010; Parasuraman et al., 1985). A study on retail stores by Dabholkar, Thorpe,andRentz(1995) empirically supported the assertion that responsiveness is an important aspect of the service quality and an antecedent of the overall service quality. Responsiveness in the mobile service providers' context refers to willingness to help customers when issues arise and provide a prompt service $(\mathrm{He} \& \mathrm{Li}, 2010)$. A study in China also proposed that responsiveness is an antecedent totheoverall service quality in the mobile services sector(Wang et al., 2004). He and $\mathrm{Li}$ (2010) suggested that responsiveness is a driver of the overall service quality in the hi-tech service industry. 


\section{Reliability}

Reliability is the ability of the firm consistently to perform the service well the first time. It also means that the firm honors its promises (Parasuraman et al., 1985). A study on retail stores empirically supported the idea that reliability is an important aspect of the service quality and an antecedent of the overall service quality (Dabholkar et al., 1995). Reliability in the context of mobile service providers refers to the accuracy and timeliness in handling customer issues and delivering their promise to customers (He\& $\mathrm{Li}, 2010)$. In today's environment, this typically involves accuracy in billing and record keeping and resolution of customer issues reported through all channels of customer service (He \& $\mathrm{Li}, 2010)$. He and $\mathrm{Li} \mathrm{(2010)}$ as well as Wang et al. (2004) proposed that reliability is an antecedent to the overall service quality in the mobile services sector.

\section{Empathy}

Empathy refers to the caring, individualized attention that a firm provides to its customers (Smith \&Reynolds, 2002; Ueltschy\&Krampf, 2001). Empathy contains the following items from the original dimensions of Parasuraman et al. (1985): communication, understanding, knowing customers, and access. Empathy is a significant driver of the overall service quality in the hi-tech service industry (He \& $\mathrm{Li}, 2010$ ). Additionally, we proposed that a personal interaction factor like empathy is important for hi-tech service firms in general and mobile service providers in particular.

\section{Methodology}

The study adopted a qualitative, inductive approach to data collection using a sample ofAustralianmobile phone users.Qualitative researchers are most concerned with richness of information; as such, sample size is not a determinant of research significance (Onwuegbuzie\& Leech, 2007). Francis et al. (2010) suggest a minimum sample size of 13 for theory-based interview studies. It was also observed in their study that study wise saturation was achieved at interview 17. This study features 21 interviews which can be considered sufficient.

Furthermore, it is acknowledged that issues can arise with bias and trustworthiness of informants. In the case of qualitative data, reliability and validity are often referred to as credibility, transferability, dependability and confirmability (Guba \& Lincoln, 1981). In order to ensure validity and reliability of the study, we followed several recommendations by previous researchers such as confirming the observations with the subjects in order to establish if the researchers' interpretation makes sense to the subject (Guba \& Lincoln, 1981). The extent to which consensus grows between the researchers and the subject is a valuable sign of trustworthiness. We also checked and cross-checked descriptions against theoretical interpretations and involved other researchers to reduce research bias (Noble \& Smith, 2015). In addition, verification strategies were conducted following Morse et al.'s (2008) recommendations, for example, ensuring sampling sufficiency, developing a dynamic relationship between sampling, data collection and analysis, thinking theoretically, and theory development. 
Semi-structured interviews were conducted with 21 participants ( 8 females and 13 males). The participants' spectrum in terms of their age and profession ranged from students to marketing executives,collegeprofessors, and chefs (Table 1). The participants in the interviews were approached via e-mail.Allthe interviews were digitally recorded and transcribed. Template analysis was employed to detect the key themes emerging from the interviews. This involves the development of codes, which underline wide themes and subsequently finer, specific themes that are significant to the study. The questions asked in the interviews mainly revolved around two important aspects:the interviewees' choice of a particular network and the value dimensions that would make them leave a particular service provider. Another important theme on which we asked questions was the consumers' usage pattern of voice and non-voice services from their current service provider.

Table 1: Demographic information of the participants

\begin{tabular}{ccccc}
\hline $\begin{array}{c}\text { Participant } \\
\text { Identification }\end{array}$ & Gender & Age & Occupation & $\begin{array}{c}\text { Mobile } \\
\text { Service } \\
\text { Provider }\end{array}$ \\
\hline AD & M & Early 20s & Marketing Professional & VF \\
AY & M & Late 30s & Program Manager & VF \\
CN & M & Late 20s & Marketing Manager & VF \\
DL & M & Early 50s & IT Administrator & EX \\
GG & F & Early 20s & Chef & OP \\
GR & M & Late 60s & Professor & VM \\
LM & F & Late 30s & Public Relations Administrator & TE \\
PT & M & Early 30s & Marketing Expert & VF \\
PI & M & Late 30s & Resource Professional & OP \\
RC & M & Late 50s & Marketing Professional & VM \\
SP & M & Late 40s & Academic Director & VM \\
TA & M & Late 50s & Academic Dean & OP \\
AG & F & Early 30s & Finance Manager & VF \\
AL & F & Late 20s & Marketing Executive & VF \\
CM & F & Late 20s & Corporate Relations & VM \\
SH & M & Late 20s & College Student & LE \\
MT & M & Early 20s & College Student & LE \\
SN & F & Late 30s & Program Manager & VF \\
CT & F & Late 20s & Administration Assistant & TE \\
DM & F & Late 20s & College Student & LE \\
SW & M & Late 50s & Supply Chain Expert & TE \\
\hline & & & &
\end{tabular}

\section{Findings}

The themes of technical capabilities and functional capabilities were a priori included, because they had been identified in the previous literature. Technical capabilities were separated into the more specific sub-themes of network quality, voice services, and non-voice services. Functional capabilities were separated into the more specific subthemes of reliability, responsiveness, and empathy.

\section{Intention to Purchase}


The intention to purchase dimensions identified consisted of: (1) network quality, (2) price value, (3) peer influence, (4) in-store service value, (5) information quality and website information support, (6) perceived brand globalness, and (7) corporate social responsibility.

\section{Network Quality}

The participants revealed that the network quality was one of the important parameters in choosing a network. They clearly said that their reason for choosing a particular network was their belief that the provider offered a better network quality.

GG: Well my contract ran out on Vo. I got the best deal on iPhone 6 with OP. Also, the signal was bad with VF.

LM: Pretty fantastic, no complaints.

MT: I chose the provider because after researching I concluded that their network is okay.

CM: Yes, the strength varies but I do get network. In the office also, some people have to go out to get network, I have never had this problem.

\section{Price Value}

The majority of the participants revealed that the price of the plan was a major attractor to the mobile service provider. Some people said that the benefits of plans were similar across providers, but the price was the differentiating factor.

PI: They had better pricing. OP had the best package that would serve my basic needs.

AD: I picked VF because I was familiar with Vodafone and the deals I was getting with others were almost the same. TE was a bit expensive.

DL: Economics of the plan. OP did not give an unlimited plan.

$\mathrm{SN}$ : One of the top three providers. TE is the best but is very expensive. VF is the second best so I chose that. Also, I was using VF back in India so that also played a part in my choice. Three main influencers were price, coverage, and brand.

\section{Peer Influence}

About half of the participants (i.e. nine) revealed that they chose a service provider because either friends or familymembersrecommended it. Moreover, in some cases, they chose a service provider because their family or friends were currently using it.

AY: I chose VF as it was recommended by a friend as the best service. 
CM: My parents were using VM and bought it for me even before I came to Australia.

PT: I changed from OP to VF because most of my friends changed.

DM: My friends were using it and they had good plans so I bought LE.

\section{In-Store Service Value}

The participants cited good in-store service value at retail stores. Moreover, they generally reported good service and interaction with sales staff as an enabler in their buying decision.

DM: The sales personnel provided me with the relevant information on various plans and helped me choose the plan that bestsuited my needs.

AY: The service at stores is excellent.

CM: Their setup is friendly and inviting, they have a kiosk kind of place which is approachable and it is not intimidating and more approachable.

MT: I bought the SIM at the airport and the salesperson was friendly and assisted me in choosing the plan.

\section{Information Quality and Website Information Support}

Based on the data collected from the interviews, information quality and website support play a major role in individuals' choice of SIM card. In many instances, people visited the website or browsed the plans online rather than physically going to the store.

MT: I browsed through the websites of different service providers before making a choice as I found it convenient to compare all the plans online on a third-party website rather than going to each mobile service provider's store separately.

DM: Yes, I do use their website sometimes for online recharge. Actually, I used their website to gather information on the plans initially as well.

However, a few of the respondents were skeptical about the information on the company websites and other online sources.

CT: I did visit many company websites before choosing a plan; however, with my experiences, usually the fine details are hidden and you come to know when you visit their store.

GG: I prefer visiting a store before choosing a provider rather than online information because the last time I visited a website it was confusing, did not have enough information on plans so I had to go to their store. 


\section{Perceived Brand Globalness}

Some participants believed that their familiarity with the brand name or their perception that the brand is a global brand had an influence on their choice of provider.

$\mathrm{CN}$ : Brand familiarity. I decided to go with something familiar.

AL: Yes, being a global brand helps in identifying it easily and gives a secure sense of choosing it.

CM: Maybe. Yeah, coz it's a very reputable brand, quite stable and it being global you still get some service out of the country.

On the contrary, most of the interviewees believed that a brand's global presence had nothing to do with their choice.

AG: No, it's just the plans and the VFM deals. Being global doesn't affect my decision.

GG: No, I don't think so. Brand origin doesn't matter much to me.

\section{Corporate Social Responsibility}

The majority of the participants interviewed shared the view that the CSR activities of a mobile service provider do not have any influence on their buying decision when choosing a service provider. However, they believed that the CSR activities of a service provider would enhance their view of that service provider's brand.

PI: Could be an element, but would not be a major one. It is good to know that a company is socially responsible but if another provider was offering half the price then I would not really care that much.

SW: No, I do not think so. The fact that I am getting a good service matters to me.

DL: I don't care about the CSR activities till I am getting value for money.

GG: CSR is irrelevant for me in buying or opting for a service provider.

However, a few of the respondents did say that giving back to society matters to them and would in fact influence their decision.

LM: Anytime they sponsor good things or help in the community are big points in my eyes. Community projects or environmental projects matter to me. If any other provider were to take initiatives, I would consider switching.

AL: Yes, CSR initiatives will influence my decision and I might pay an extra few dollars if a service provider is doing it. 


\section{Intention to Switch}

The participants' responses revealed seven value dimensions for the intention to switch based on their experiences with their present or previous service providers. While some value dimensions are the same as for theintention to purchase, others are unique to the intention to switch. Specifically, the participants cited functional values, like reliability, responsiveness, empathy, and privacy, as influencers on their decision to switch. Moreover, the network quality emerged as a major determinant for people who wanted to switch.

\section{Network Quality}

Most of the participants were not happy with their network to a certain degree. Contrary to people's perception, the network quality for some providers was not as good as expected.

$\mathrm{CN}$ : Voice quality, data speed is good but I do face network coverage issues at home andin the workplace. That's probably the biggest dissatisfaction I have.

AD: I'd rate it as average because at some places I get zero bars in my house and workplace. It's not too often.

AL: It's okay. I don't get network in remote areas.

GG: Not as good as I thought but better than VF. Voice quality is good.

Some participants revealed that they were unhappy with their network and would be willing to switch or had thought about switching to another network to obtainbetter coverage.

DL: If somebody offered a better plan with better coverage, I would.

AD: Better network coverage and same plan money wise. I'd switch to TE because they have really good network coverage.

$\mathrm{CN}$ : Yes, I was at one point considering moving to OP purely for coverage because my roommate was getting great coverage.

\section{Voice Services}

The voice offering as a service plays a pivotal role in customers' decision to stay with a network or switch to a different network. The voice quality is generally good for every service provider and depends upon the network quality. However, the voice service plans offered by different providers are the major differentiator, which became apparent in the answers of the respondents.

SP: Overseas voice plans get my attention. Being an expat, it interests me. I have 60 minutes per month as of now, which is much less for me. 
SN: I usually call overseas. So if any service provider comes up with attractive overseas voice plans, I might switch to it.

RC: I am using this provider because it gives me unlimited calls to people on the same network and my whole family uses the same provider so we can call free to each other.

\section{Non-Voice Services}

Many respondents in our interviewsreportedthat they do not just use their mobile phone to make calls; they use other non-voice servicesas well. Data usage, messaging, and other value-added services played a major role in their decision to stay with their provider or move to another network.

SN: I use the data services extensively. I run out of it quite often.

AL: Yes, 9 out of 10 times. I am more into data services.

CM: I use data for music streaming, web-browsing, apps, etc.

\section{Reliability}

The participants reported most of the service providers to be reliable.

AD: I use online billing mostly; that too is an automatic setup. So, I hardly look into it but I have never seen any false billing.

CN: They understand my needs and yes, they go to great lengths to figure out my problems so they are good at it.

RC: I have used other providers in the past and VM is definitely more reliable. It exceeds my level of satisfaction and they are doing a great job.

However, certain participants reported that the service providers were not so reliable. Interestingly, reliability does not affect the intention to switch to a great extent.

AL: They were too busy and if I asked something, they just referred me to their website.

PI: Experienced that credit seemed to disappear a few times.

PT: I had an experience where I was getting promotional calls. The customer service employee was not able to fix this the first time.

\section{Responsiveness}

The majority of the participants believed that the service providers had been responsive to their needs and quick to resolve issues and this led to overall service quality and satisfaction. 
AD: I get immediate call back and am allowed to jump the queue in the stores.

$\mathrm{CN}$ : They are quick. I had an issue once but they were pretty professional and quick.

GR: I rarely deal with customer service but I contacted them online once and they were quick.

\section{Empathy}

Most participants had favorable experiences with customer service. They believed that the customer service professionals of the providers understand their needs and are empathetic towards them.

AD: The customer service is brilliant; they understand my needs and problems and are quick to resolve the same.

TA: The customer service is good; they usually understand my needs and problems and are quick to resolve the same.

SN: They understand my needs reasonably well.

\section{Privacy}

Most of the participants revealed that privacy and security are an important factor affecting their decision to stay with a particular provider. However, the participants who had faced no issues in this context did not give this attribute much importance.

AL: Yes, I do feel secure. I click on links in their official e-mails.

MT: I feel that websites of providers are generally secure.

On the contrary, people with negative experiences felt extremely dissatisfied with any breach of security or privacy.

$\mathrm{SN}$ : One problem I faced was that they could not take care of the fact that I was receiving promotional messages on my phone. They asked me to change my number or file a police complaint rather than taking care of the problem.

DM: Spam messages are a big problem. Even though I have complained a few times, I still face this issue.

\section{Kano Model}

The findings were found to be in line with the Kano Model. It classifies customer preferences into different categories (Table 2 and Figure 1). 
1. Performance is the main point of assessment and is often called "onedimensional" because the better it is executed, the more satisfied the customers are.

2. Basic or must be qualities are the requirements that the customers expect and are taken for granted. If performed well, they do not affect customer satisfaction, but customer satisfaction is damaged if they are performed poorly.

3. Delighters are the requirements that are unexpected and pleasant innovations. They delight the customer when present but do not cause dissatisfaction if they are missing.

Table 2: The Kano Model - categorization according to our analysis of participant responses

\begin{tabular}{ccc}
\hline Delighters & Performance & Must Be \\
\hline Innovations & Network Quality & Privacy \\
CSR Activities & Voice Services & Reliability \\
Empathy & Non-Voice Services & Responsiveness \\
\hline
\end{tabular}

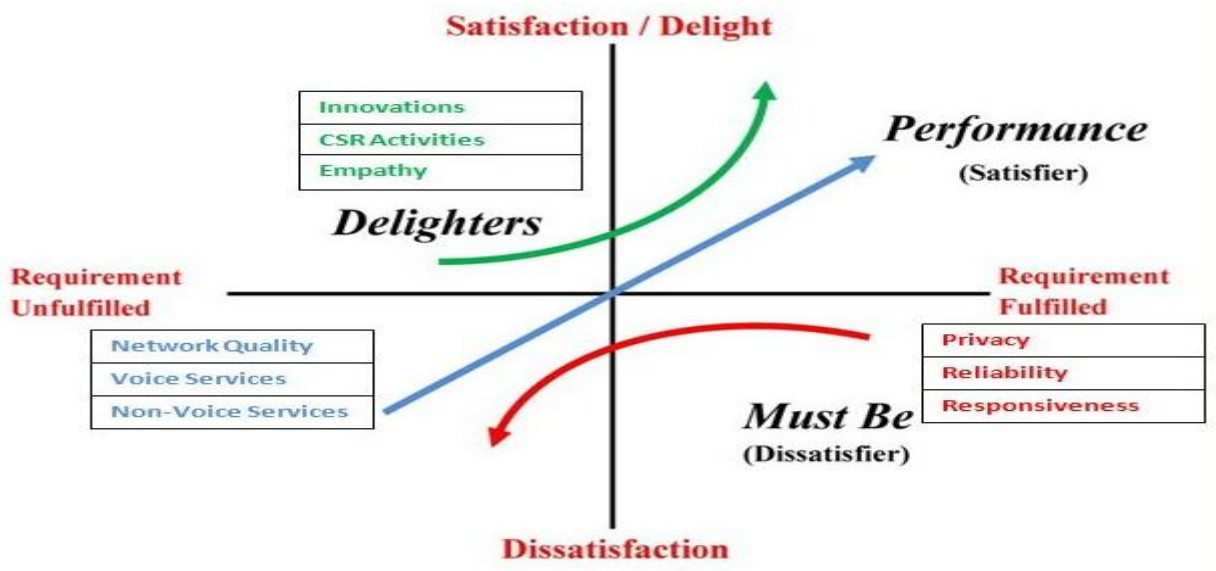

Figure 1: The Kano Model - categorization according to our analysis of Participant responses

In short, seven value dimensions for the intention to purchase and seven value dimensions fortheintention to switch emerged from the interview data. The intention to purchase value dimensions were identified based on an understanding of customers' purchase motivations and how these motivations affect customers' overall satisfaction and perceived value. The intention to switch dimensions were identified based on customers' motivations to switch their service provider and how these motivations affect customers' overall satisfaction and perceived value (Table 3 ). 
Table 3: Consumers' intention value types and dimensions

\begin{tabular}{|c|c|c|}
\hline $\begin{array}{l}\text { Value } \\
\text { type }\end{array}$ & $\begin{array}{l}\text { Value dimension } \\
\text { within each value } \\
\text { type }\end{array}$ & Definition of value types \\
\hline \multirow{7}{*}{$\begin{array}{l}\text { Intention } \\
\text { to } \\
\text { purchase }\end{array}$} & Network quality & Network performance and connectivity to other networks \\
\hline & Price value & Perceived monetary saving from low product prices \\
\hline & Peer influence & $\begin{array}{l}\text { A kind of intangible power exerted by peers that may } \\
\text { change people's perception and intent }\end{array}$ \\
\hline & $\begin{array}{l}\text { In-store service } \\
\text { value }\end{array}$ & $\begin{array}{l}\text { Perceived customer service excellence inside the retail } \\
\text { store }\end{array}$ \\
\hline & $\begin{array}{l}\text { Information quality } \\
\text { and website } \\
\text { information support }\end{array}$ & $\begin{array}{l}\text { The quality of information available to customers } \\
\text { through the company website, online customer support, } \\
\text { and other communication channels }\end{array}$ \\
\hline & $\begin{array}{l}\text { Perceived brand } \\
\text { globalness }\end{array}$ & $\begin{array}{l}\text { The degree to which the consumers believe that the } \\
\text { brand is marketed in multiple countries and is recognized } \\
\text { as "global" in those countries }\end{array}$ \\
\hline & $\begin{array}{l}\text { Corporate social } \\
\text { responsibility }\end{array}$ & $\begin{array}{l}\text { The integration of corporate self-regulation into the } \\
\text { business model to embrace responsibility for corporate } \\
\text { actions and encourage social good }\end{array}$ \\
\hline \multirow{7}{*}{$\begin{array}{l}\text { Intention } \\
\text { to switch }\end{array}$} & Network quality & Network performance and connectivity to other networks \\
\hline & Voice services & Primary services, i.e. making and receiving a call \\
\hline & Non-voice services & $\begin{array}{l}\text { Value-added services offered by the service provider, } \\
\text { like GPRS, e-mail, and MMS }\end{array}$ \\
\hline & Reliability & $\begin{array}{l}\text { Willingness of personnel to provide a prompt service and } \\
\text { assistance to the customer }\end{array}$ \\
\hline & Responsiveness & $\begin{array}{l}\text { Ability of the firm consistently to perform the service } \\
\text { well the first time }\end{array}$ \\
\hline & Empathy & $\begin{array}{l}\text { The caring, individual attention that the firm provides to } \\
\text { its customers }\end{array}$ \\
\hline & Privacy & $\begin{array}{l}\text { A sense of feeling safe when using the service and the } \\
\text { privacy of shared information }\end{array}$ \\
\hline
\end{tabular}

\section{Discussion}

Service providers strive to deliver customer value to differentiate their serviceandcreate a competitive advantage. Although researchers have investigated the perceived value for customers, there has been little agreement over its meaning and drivers. This study examined consumer brand value from a holistic viewpoint, identifying the inception of value from unsatisfied customer needs to customers' intention to purchase and intention to switch. Perceived value emerges from satisfying customers' needs and wants.

Based on the findings, it can be argued that the price value and network quality play a major role in the intention to purchase of a Mobile Service Provider. Peer influence has affected customers' intention to purchase positively, as none of the interviewees reported that they had overlooked a network provider because of peer influence. Instore service value played a small role in the intention to purchase, and the participants reported good service and interaction with sales staff as an enabler in 
their buying decision. Information quality and website information support act as a catalyst and help the users in narrowing down their options, but the final decision is usually made after visiting the stores. Perceived brand globalnesswas not identified as a major influencer by most of the respondents. However, most of the expats reported perceived brand globalnessto be one of the influencers in their choice of service provider as it has an impact on the credibility, prestige, and quality of a brand. Global brands are perceived to deliver high quality because consumers assume that brands that are accepted worldwide would not be successful if they were not high quality (Özsomer, 2012). CSRwas mentioned as a purchase intent value by a few female participants. However, most of the respondents believed that they would not care much about the CSR activities when making a purchase.

Network quality also plays an important role in the intention to switch. Most of the respondents who reported their network quality to be poor intended to switch. Moreover, some respondents who had switched network providers in the past cited the network quality as one of the reasons. Participants suggested that they might switch if their family or friends on the same network also switched or if they receivedan offer that provides free calls to other networks. Non-voice services, especially messaging and data, influence the intention to switch. Heavy messaging users look for unlimited messaging offers that are available in the marketplace. Some of the participants reported that they usually run over their current data plan and are charged more for exceeding the limit. In addition, reliability and responsiveness do not affect the intention to switch to a great extent. However, empathy plays an important role in the intention to switch. Most of the participants believed that the service provider takes care of their privacy and security. However, a few of the participants believed that privacy and security are sometimes ignored by the service providers. They also reported that privacy is of the utmost concern to them and would lead them to switch their network provider.

\section{Managerial implications and future research directions}

The managerial implications and limitations and future research directions are presented in turn below.

\section{Managerial implications}

The telecommunications industry has witnessed high switching rates (Thaichon, Lobo, Prentice \& Quach, 2014). Many companies try to acquire new customers through price competition, which might lead to a vulnerable and imbalanced market in which smaller companies with low capital cannot compete against major corporations. Such competition can also deteriorate the firms' performance as well as services infrastructure. This study proposes a solution to this issue by investigating the determinants of customer satisfaction, overall service quality and consumers' intention values with a view to achieving the sustainable development of the telecommunications industry as a whole. This will form a foundation for mobile service provider to develop new retention strategies. As a result, mobile service providers will be able to reduce the current issues relating to their customers switching providers in the Australian market and in other countries that have similar demographic profiles. 


\section{Limitations and future research directions}

This study was empirically tested using data of mobile customers in Australia which could be different for customers in other service industries as well as in other countries. In the interest of generalisation, future research should be conducted to test this model in other service contexts in countries like Thailand, Vietnam and Cambodia. In addition, this study fell short in examining all the relationships between the affective evaluation constructs, i.e. between customer satisfaction, value, trust and commitment. Future research should investigate these relationships in order to better understand the effects of service quality in a more challenging customer environment.

\section{References}

Adegoke, Y., (2002),Non-voice services help to revive mobile user revenues. New Media Age, 16.

Asaari, M. H. A. H., and Karia, N., (2003), "Business strategy: Customer satisfaction among cellular providers in Malaysia", The European Applied Business Research Conference Proc., Venice, Italy.

Dabholkar, P. A., Thorpe, D. I., and Rentz, J. O., (1995), "A measure of service quality for retail stores: Scale development and validation", Journal of the Academy of Marketing Science, vol. 24, no.1, pp. 3-16.

Francis, J., Johnston, M., Robertson, C., Glidewell, L., Entwistle, V., Eccles, M., and Grimshaw, J., (2010), "What is an adequate sample size?Operationalising data saturation for theory-based interview studies", Psychology \& Health, vol. 25, no. 10, pp. 1229-1245.

Han, S., Lu, S., and Leung, S., (2012), "Segmentation of telecom customers based on customer lifetime value by decision tree model", Expert Systems With Applications, vol. 39, pp. 3964-3973.

He, H., and Li, Y., (2010), "Key service drivers for high-tech service brand equity: The mediating role of overall service quality and perceived value", Journal of Marketing Management, vol. 27, no.1-2, pp. 77-99.

Kim, H., and Yoon, C., (2004), "Determinants of subscriber churn and customer loyalty in the Korean mobile telephony market", Telecommunications Policy, vol. 28, no. 9, pp. 751-765.

Morse, J. M., Barrett, M., Mayan, M., Olson, K., and Spiers, J., (2008), "Verification strategies for establishing reliability and validity in qualitative research", International journal of qualitative methods, vol. 1, no. 2, pp. 13-22.

Noble, H., and Smith, J., (2015), "Issues of validity and reliability in qualitative research", Evidence Based Nursing, vol. 18, no. 2, pp.34-35.

Oh, S., Yang, S., Kurnia, S., Lee, H., Mackay, M., and O’Doherty, K., (2008), “The characteristics of mobile data service users in Australia", International Journal of Mobile Communications, vol. 6, no.2, pp. 217-230.

Onwuegbuzie, A. J., and Leech, N. L., (2007), "A call for qualitative power analyses", Quality \& Quantity, vol. 41, no. 1, pp. 105-121.

Özsomer, A., (2012), "The interplay between global and local brands: A closer look at perceived brand globalness and local iconness", Journal of International Marketing, vol. 20,no.2, pp.72-95.

Parasuraman, A., Zeithaml, V. A., and Berry, L. L., (1985), "A conceptual model of service quality and its implications for future research", Journal of Marketing, pp. 41-50. 
Parasuraman, A., Zeithaml, V. A., and Berry, L. L., (1988), SERVQUAL: A multipleitem scale for measuring consumer perceptions of service quality", Journal of Retailing, vol. 64, pp. 12-40.

Paulrajan, R., and Rajkumar, H., (2011), "Service quality and customers preference of cellular mobile service providers", Journal of Technology Management and Innovation, vol. 6, no.1, pp. 38-45.

Rust, R. T., and Chung, T. S., (2006), "Marketing models of service and relationships", Marketing Science, vol. 25, no. 6, pp. 560-580.

Smith, A. M., and Reynolds, N. L., (2002), "Measuring cross-cultural service quality: A framework for assessment", International Marketing Review, vol. 19, no.4/5, pp. $450-481$.

Steward, S., (1993), “Testing equipment roundup”, Cellular Business, vol.10, no.9.

Thaichon, P., and Quach, T. N., (2015), "The relationship between service quality, satisfaction, trust, value, commitment and loyalty of Internet service providers' customers", Journal of Global Scholars of Marketing Science, vol. 25, no. 4, 295-313.

Thaichon, P., Lobo, A., and Mitsis, A., (2014), "An empirical model of home internet services quality in Thailand", Asia Pacific Journal of Marketing and Logistics, vol. 26, no.2, pp. 190-210.

Thaichon, P., Lobo, A., Prentice, C., and Quach, T. N., (2014), "The development of service quality dimensions for Internet service providers: Retaining customers of different usage patterns," Journal of Retailing and Consumer Services, vol. 21, pp. 1047-1058.

Ueltschy, L.C., and Krampf, R. F., (2001), "Cultural sensitivity to satisfaction and service quality measures", Journal of Marketing Theory and Practice, vol. 9, no.3, pp. 14-31.

Vlachos, A., and Vrechopoulos, P., (2008), "Determinants of behavioral intentions in the mobile internet services market", Journal of Services Marketing, vol. 22, no. 4, pp. 280-291.

Wang, C., and Wu, L., (2012), "Customer loyalty and the role of relationship length", Managing Service Quality, vol. 22, no.1, pp. 58-74.

Wang, Y., Lo, H. P., and Yang, Y., (2004), "An integrated framework for service quality, customer value, satisfaction: Evidence from China's telecommunication industry", Information Systems Frontiers, vol. 6, no. 4, pp. 325-340.

Wishart, N., (2006),"Micro-payment systems and their application to mobile networks",WashingtonDC:InfoDev. Retrieved from http://www.infodev.org/en/Publication.43.html 